University of Nebraska - Lincoln

DigitalCommons@University of Nebraska - Lincoln

USDA National Wildlife Research Center - Staff Publications
U.S. Department of Agriculture: Animal and Plant Health Inspection Service

2010

\title{
Habitat succession, hardwood encroachment and raccoons as limiting factors for Lower Keys marsh rabbits
}

Paige M. Schmidt

Texas A\&M University, paige.m.schmidt@aphis.usda.gov

Robert A. McCleery

Texas A\&M University, ramccleery@ufl.edi

Roel R. Lopez

Texas A\&M University, roel@tamu.edu

Nova J. Silvy

Texas A\&M University, n-silvy@tamu.edu

Jason A. Schmidt

Texas A\&M University, jason.a.schmidt@aphis.usda.gov

Follow this and additional works at: https://digitalcommons.unl.edu/icwdm_usdanwrc

Schmidt, Paige M.; McCleery, Robert A.; Lopez, Roel R.; Silvy, Nova J.; and Schmidt, Jason A., "Habitat succession, hardwood encroachment and raccoons as limiting factors for Lower Keys marsh rabbits" (2010). USDA National Wildlife Research Center - Staff Publications. 1282.

https://digitalcommons.unl.edu/icwdm_usdanwrc/1282

This Article is brought to you for free and open access by the U.S. Department of Agriculture: Animal and Plant Health Inspection Service at DigitalCommons@University of Nebraska - Lincoln. It has been accepted for inclusion in USDA National Wildlife Research Center - Staff Publications by an authorized administrator of DigitalCommons@University of Nebraska - Lincoln. 


\title{
Habitat succession, hardwood encroachment and raccoons as limiting factors for Lower Keys marsh rabbits
}

\author{
Paige M. Schmidt ${ }^{*, 1}$, Robert A. McCleery ${ }^{2}$, Roel R. Lopez, Nova J. Silvy, Jason A. Schmidt ${ }^{1}$ \\ Texas AEM University, Department of Wildlife and Fisheries Sciences, 210 Nagle Hall, College Station, TX 77840, USA
}

\section{A R T I C L E I N F O}

\section{Article history:}

Received 25 March 2010

Received in revised form 14 June 2010

Accepted 15 July 2010

Available online 8 August 2010

\section{Keywords:}

Density

Habitat succession

Hardwood encroachment

Lagomorphs

Raccoon

Sylvilagus palustris hefneri

\begin{abstract}
A B S T R A C T
The Lower Keys marsh rabbit (LKMR, Sylvilagus palustris hefneri), a marsh rabbit subspecies endemic to the Lower Keys, Florida was protected in 1990, however, populations continue to decline despite recovery efforts. We hypothesized on-going habitat loss and fragmentation due to succession and hardwood encroachment has lead to increased edge, reduced habitat quality, and increased activity by native raccoons (Procyon lotor). These factors reduce the suitability of patches in a later successional state, thus threatening LKMR recovery and metapopulation persistence. We surveyed 150 LKMR patches in 2008, tallying adult and juvenile rabbit pellets, estimating measures of habitat succession and quality (woody and herbaceous ground cover, distribution of herbaceous species) and recording raccoon activity (number of raccoon signs). We calculated patch edge (patch shape index) using ArcGIS. We evaluated the relationship between patch and habitat attributes and LKMR using regression analysis and model selection. We found both adult and juvenile LKMR pellet counts were lower in patches with higher shape indices and higher in patches with greater occurrence of bunchgrasses and forbs. We also found adult LKMR pellet counts were lower in patches with higher raccoon activity. Our results suggest patch edge, habitat succession and quality, and raccoons pose a threat to the persistence and recovery of LKMR populations. Recovery efforts should focus on reducing these trends through habitat management and raccoon removal implemented in carefully controlled experiments with proper monitoring. Measures of patch and habitat attributes important to LKMR should be incorporated into long-term metapopulation monitoring and used to evaluate recovery actions.
\end{abstract}

Published by Elsevier Ltd.

\section{Introduction}

Metapopulations are composed of spatially discrete local populations connected by dispersal and maintained by an equilibrium rate of patch extinction and colonization (Levins, 1970). This framework has been useful for the study of species threatened with extinction by habitat loss and fragmentation (Harrison, 1994; Litvaitis and Villafuerte, 1996) and species that occur in successional habitats maintained by disturbance (Litvaitis, 1993). Advances in metapopulation theory have accounted for the effect of patch succession on population persistence (Ellner and Fussmann, 2003;

\footnotetext{
* Corresponding author. Present Address: USDA-APHIS Wildlife Services National Wildlife Research Center, Ohio Field Station, 6100 Columbus Avenue, Sandusky, OH 44870, USA. Tel.: +1 419625 0242; fax: +1 4196258465.

E-mail addresses: paige.m.schmidt@aphis.usda.gov (P.M. Schmidt), ramccleery@ufl.edu (R.A. McCleery), roel@tamu.edu (R.R. Lopez), n-silvy@tamu.edu (N.J. Silvy), jason.a.schmidt@aphis.usda.gov (J.A. Schmidt).

1 Present address: USDA-APHIS Wildlife Services, National Wildlife Research Center, Ohio Field Station, 6100 Columbus Avenue, Sandusky, OH 44870, USA.

2 Present address: University of Florida, Department of Wildlife Ecology and Conservation, Newins-Ziegler Hall, P.O. Box 110430, Gainesville, FL 32611, USA.
}

Hastings, 2003; Johnson, 2000; Thomas, 1994), but this has rarely been demonstrated empirically (Amarasekare and Possingham, 2001; Stelter et al., 1997). An empirical understanding of the influence of succession within each patch and on an entire metapopulation is critical to the recovery of species dependent on early successional habitats and threatened by habitat loss and fragmentation (Litvaitis, 1993). Species dependent on early successional habitats have been vulnerable to the effects of fragmentation because it can increase rates of habitat succession through hardwood encroachment and the associated edge effects might reduce their distribution, hinder their dispersal abilities, and increase rates of predation and parasitism (Dijak and Thompson, 2000; Hardt and Forman, 1989; Yahner, 1988).

Lagomorph species throughout the world are threatened with extinction due to habitat loss and degradation, over-exploitation, competition (heterospecifics and introduced lagomorphs), and predation (IUCN, 2010; Smith, 2008). Numerous lagomorphs of conservation concern occur as metapopulations and are dependent upon successional habitats (e.g., Lower Keys marsh rabbits [Sylvilagus palustris hefneri]: Forys and Humphrey, 1996; New England cottontail [Sylvilagus transitionalis]: Litvaitis and Villafuerte, 
1996; riparian brush rabbit [Sylvilagus bachmani riparius]: Williams et al., 2008; swamp rabbit [Sylvilagus aquaticus]: Nielsen et al., 2008). Conservation and recovery efforts for these and other lagomorphs can be difficult when basic population ecology data are lacking (Hackländer et al., 2008). This is the case with the Lower Keys marsh rabbits (LKMR), which lacks information on the particular factors driving persistence of local populations and information specific to juvenile rabbits.

The LKMR is a marsh rabbit subspecies (Lazell, 1984) listed as endangered by the US Fish and Wildlife Service (USFWS) and the Florida Fish and Wildlife Conservation Commission since 1990 (USFWS, 1990). LKMR are endemic to the Lower Keys, Florida, that form the end of a chain of limestone islands extending south and west from the southern tip of peninsular Florida (Fig. 1). Despite recovery efforts, LKMR populations continued to decline (USFWS, 2007). Threats to LKMR have changed since the initial recovery plan was developed over a decade ago. For example, off-road vehicle mortality was abated due to restriction of off-road vehicle use in areas critical to LKMR, and the threat of habitat loss from development was reduced due to state and federal regulatory oversight (USFWS, 2007). During this same time, however, the habitat has been fragmented or degraded due to succession and hardwood encroachment (Perry, 2006; USFWS, 2007), and a new threat, raccoons (Procyon lotor), has been recognized (USFWS, 2007).

LKMR typically occupy wet areas with dense cover including salt marsh, buttonwood (Conocarpus erectus) transition zones, and freshwater marshes (Faulhaber et al., 2007, 2008; Forys, 1995). LKMR use habitats with dense, low ( $<1 \mathrm{~m}$ ) forbs and grasses and little overstory vegetation, and avoid areas in a later state of succession characterized by mature buttonwoods, high canopy cover and low ground cover (Faulhaber et al., 2008; Perry, 2006). Hardwood encroachment of coastal wetlands has been documented for the Lower Keys, Florida and has been attributed to LKMR population declines observed over the past three decades (Alexander and Dickson, 1970; Dickson, 1955; Perry, 2006; USFWS, 1999).

Changes in disturbance regimes along with habitat fragmentation could have reduced availability of early successional habitats used by LKMR. Hurricanes are a common disturbance event in the Keys, but storm surges associated with hurricanes, such as those following Hurricanes Betsy in 1965, Georges in 1998, and Wilma in 2005 are less common (Lopez et al., 2003; Kasper, 2005). The Lower Keys have a maximum elevation of $3 \mathrm{~m}$ making these islands and their habitats highly susceptible to storm surges (McGarry MacAulay et al., 1994). The expected regeneration of early successional habitats may not occur or could be delayed when a storm surge causes damage to vegetation or results in a detritus layer that prevents regeneration of herbaceous vegetation. Further, fire from early Native Americans, lightning strikes, or from adjacent fire-dependent habitats (e.g., pine rocklands) is integral to the ecology of the Lower Florida Keys but has been suppressed in the Lower Keys since the 1960s (USFWS, 2000). Prior to this period, accounts noted the open nature of coastal salt marsh prairies in areas historically occupied by LKMR, areas now in a climax successional state (N. Silvy, Texas A\&M University, unpublished data). Additionally, early settlers of the Lower Keys harvested buttonwood from coastal salt marsh prairies to produce charcoal, a process that would have reduced hardwoods and created patches of open prairie (Viele, 1996).

Free-roaming domestic cat (Felis catus) predation was responsible for $50 \%$ of adult LKMR mortality and was cited as the largest factor limiting their population viability in the 1990s (Forys and Humphrey, 1999a). Nonetheless, free-roaming domestic cat removal initiated on Boca Chica Key indicated raccoons were an order of magnitude more prevalent than cats in treated areas (235 raccoons vs. 20 cats; USFWS, 2007). Raccoons, although omnivorous, have been shown to be efficient predators and to prey on rabbits (Dorney, 1954; Howe, 1988 [Unpublished status survey]; Jennings et al., 2006; Urban, 1970) and might pose a risk to LKMR, particularly nestlings, because of their susceptibility to predation (Howe, 1988 [Unpublished status survey]; USFWS, 2007). This might be exasperated by the fact that raccoons reach high densities in anthropogenically altered landscapes and marsh habitats interspersed with hardwoods, habitats that are characteristic of many LKMR patches (Dorney, 1954; McCleery et al., 2005; Riley et al., 1998; Smith and Engeman, 2002).

LKMR habitats are small, averaging $\approx 4$ ha, and are distributed in discrete patches or sites, that function as a classic metapopulation (Forys and Humphrey, 1996, 1999a; USFWS, 1999). Subadult LKMRs are largely responsible for inter-patch dynamics through

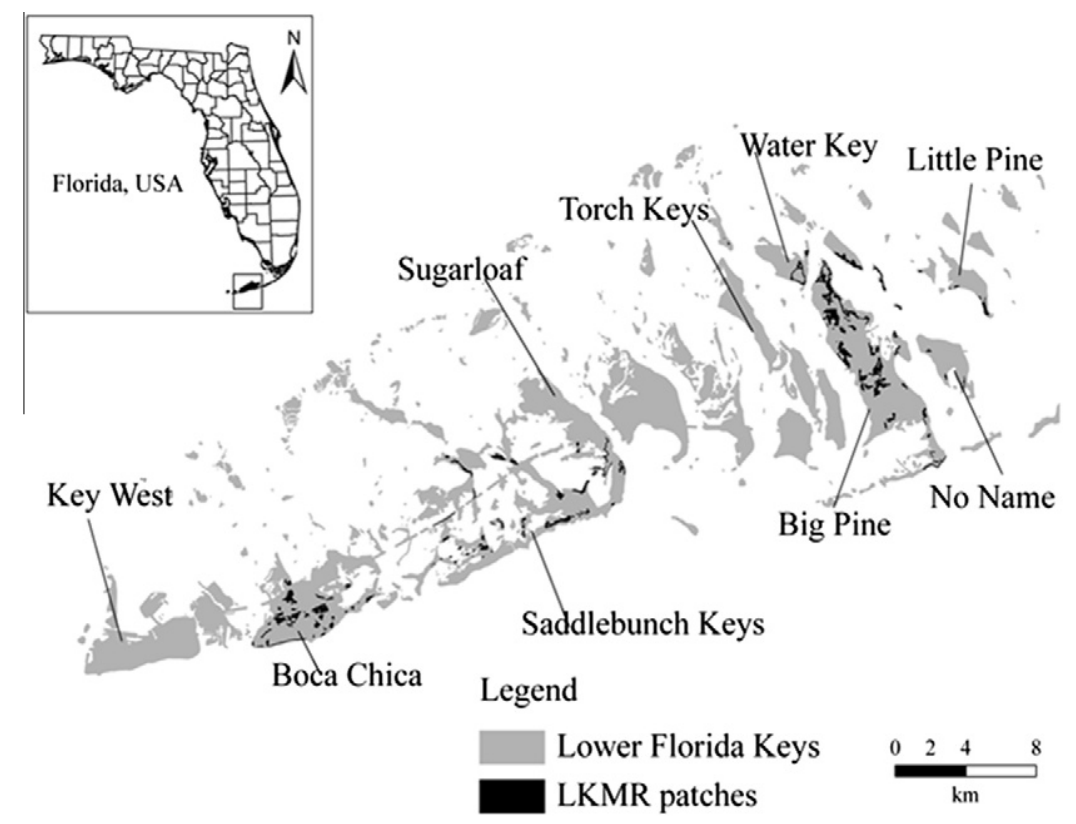

Fig. 1. Distribution of Lower Keys marsh rabbit patches throughout the Lower Keys, Florida, USA. 
one-way dispersal from natal patches (Forys, 1995; Forys and Humphrey, 1996). Previous research has shown that only half of consistently occupied patches (Forys and Humphrey, 1999b) were producing the juveniles that drive inter-patch dynamics and determine metapopulation persistence. The effects of patch and habitat attributes on juvenile LKMR populations have not previously been evaluated, yet remain vital to successful implementation of recovery strategies for this subspecies.

The purpose of our study was to examine the relationship between LKMR and factors thought to impede their recovery. Specifically, we wanted to determine if the relative portion of edge and measures of habitat succession, habitat quality and raccoon activity influenced the sizes of local adult and juvenile LKMR populations. This information can be used to evaluate on-going recovery efforts and to develop new recovery strategies and actions that could then be incorporated into an adaptive resource management plan for the rabbits (Lancia et al., 1996; Perry, 2006).

\section{Methods}

\subsection{Study area}

The Lower Keys, Florida, are located between 23.5 and $25.5^{\circ} \mathrm{N}$ latitude and exhibit a subtropical climate due to the Gulf Stream and other maritime influences (Fig. 1; Chen and Gerber, 1990; Forys and Humphrey, 1999a). The climate is characterized by distinct wet and dry seasons, with the dry season (November through April) contributing $<33 \%$ of annual precipitation (Forys and Humphrey, 1999a). Elevation rarely exceeds $2 \mathrm{~m}$, with slight variations in elevation producing distinct vegetation communities that transition from mangroves to coastal salt marsh/buttonwood transition zones inland to freshwater marshes, pine rocklands and tropical hardwood hammocks (McGarry MacAulay et al., 1994).

LKMR are predominately found in coastal salt marsh prairies and freshwater marshes (Faulhaber et al., 2007). Coastal salt marsh prairies, also known as buttonwood transitions zones, are characterized by cord grasses (Spartina spartinae, Spartina patens, Spartina bakeri), sea daisies (Borrichia frutescens, Borrichia arborescens), glassworts (Salicornia spp.), seashore dropseed (Sporobolus virginicus) and rushes (family Cyperaceae) with various densities of salt tolerant hardwoods depending on disturbance history (e.g., fire, cutting) and salinity (Faulhaber, 2003). The hardwoods are predominantly buttonwood but include white mangrove (Laguncularia racemosa), red mangrove (Rhizophora mangle), black mangrove (Avicennia germinans), joewood (Jaquinia keyensis), poisonwood (Metopium toxiferum), and wild dilly (Manilkara bahamensis). Freshwater marshes are characterized by sawgrass (Cladium jamaicensis) and Gulf Coast spike rush (Eleocharis cellulose) interspersed with buttonwood (C. erectus) and other hardwoods also dependent upon disturbance history (e.g., fire, cutting) and salinity. Invasive exotic plant species also are distributed throughout the range of the LKMR and have been identified as a source of habitat loss and degradation. The most prevalent species form thick monocultures and include Australian pine (Casuarina equisitifolia), Brazilian pepper (Schinus terebinthifolia), lead tree (Leucaena leucocephala), and mahoe (Hibiscus tiliaceus).

\subsection{Fecal pellet sampling}

We sampled the entire known range of the LKMR by surveying patches identified from an updated distribution survey (Fig. 1; Faulhaber et al., 2007). We used protocols established by Schmidt et al. (in press) for fecal pellet sampling. We constructed a digital grid with nodes placed $30 \times 30$-m apart and placed it over a shapefile of the Lower Keys, Florida using a Geographic Information Sys- tem (GIS; ArcGIS 9.3, ESRI, 2008). Grid nodes falling within the boundaries of LKMR patches were selected and stored within the GIS. We navigated to grid nodes within each patch using a global positioning system, searched within a $1-\mathrm{m}$ radius of each node (sample unit) for LKMR pellets, and quantified parameters hypothesized to influence their numbers. We separated and tallied LKMR fecal pellets by age class (juvenile and adult pellets/node) to determine if ecological parameters affecting the rabbits differed for adults and juveniles. Incidences of fecal pellets have been shown to have a strong correlation with LKMR density and rabbit age is easily determined by pellet diameter (Forys, 1995; Schmidt et al., in press). To determine rabbit age, we constructed a diagram on every data sheet that indicated the minimum diameter of an adult LKMR pellet. Pellets that were less than the minimum diameter of an adult pellet were recorded as juveniles; pellets that were larger than the minimum diameter were recorded as adults.

\subsection{Estimation of patch and habitat attributes}

As an indicator of patch edge, we measured patch area and perimeter using a GIS which we then used to calculate a patch shape index ( $p s i)$ using the following equation for vector data:

patch shape index $(p s i)=$ perimeter $(\mathrm{m}) / \sqrt{4 \times \pi \times \text { area }}\left(\mathrm{m}^{2}\right)$.

Patch shape indices estimate a perimeter to area ratio while standardizing for patch area (McGarigal and Marks, 1995). Patch shape indices range from 1 to $\infty$ with an index of 1 indicating a perfectly circular shape whereas, higher values show that the amount of edge relative to patch interior is increasing in complexity. Edge effects have been shown to reduce a vertebrate species' distribution and dispersal ability and increase rates of predation and parasitism (reviewed by Yahner, 1988). Boundary shape also has been associated with rates of woody plant encroachment or habitat succession (Hardt and Forman, 1989).

As an indicator of habitat succession and quality, we visually estimated foliar cover (\%) of woody (woody) and herbaceous (herb) vegetation $<0.5 \mathrm{~m}$ in height within each $1-\mathrm{m}$ radius sample unit. For each sample unit, we visually estimated the total cover for each category (woody and herb) to the nearest $5 \%$. We summed woody and herbaceous ground cover estimates for all sample units within a patch to obtain patch totals. The structure of vegetation, including vegetation height and thickness of foliar cover has been shown to be important in the selection of diurnal forms or resting sites used by LKMR in both saltwater and freshwater marshes (Faulhaber et al., 2008). Perry (2006) characterized hardwood encroachment detrimental to LKMR habitat suitability as decreased ground cover vegetation and height.

We also measured habitat succession and quality by quantifying the distribution within each patch of four genera of bunchgrasses and forbs important to LKMR for food, cover and nesting (Faulhaber et al., 2008; Forys and Humphrey, 1999b). We recorded the presence of cord grasses, sea daisies, bluestems (Andropogon glomeratus, Andropogon virginicus), and spike rush within each sample unit. We summed occurrences of these four herbaceous plant genera for all sample units within a patch to obtain patch totals (dist). Bunchgrass density and presence of forbs have been found to decline with increasing hardwood encroachment in LKMR habitat (Perry, 2006). These species also have been found to be important indicators of consistency of patch occupancy (Forys and Humphrey, 1999b).

We quantified a measure of raccoon activity (proc) by recording the presence or absence of raccoon scat and tracks at each sample unit. We then summed the total number of sample units where raccoon signs were present to create a discrete estimate of raccoon activity for each patch. 


\subsection{Data analysis}

To determine patch and habitat attributes with the greatest influence on the LKMR, we used generalized linear regressions and maximum likelihood estimation to relate patch and habitat variables to pellet counts. We evaluated model sets specific to adult and juvenile LKMR fitted to a negative binomial distribution using SPSS software (Release 15.0.0, 2006). The negative binomial distribution contains an additional parameter that allows the variance to be greater than the mean and is appropriate for use when the count of failures, in this case the number of patches without rabbits, is greater than expected by the Poisson distribution (Agresti, 2007). We included the log of the total number of sample units per patch as an offset term in all regression models to account for autocorrelation between sampling efforts and patch area (Agresti, 2007). Offset terms in regressions of count data maintain the proportionality of the response variable to the explanatory variable(s) so that a doubling of the number of sample units would correspond with a doubling of the expected outcome, in this case the number of pellets per patch.

To evaluate the effect of patch edge or complexity, habitat succession and quality, and raccoon activity on LKMR, we evaluated 31 a priori models including a global model containing all six variables and an intercept-only (null) model for adult (Table 1, models 1-31) and juvenile (Table 2, models 32-62) rabbits. We evaluated the additive and interactive effects of patch complexity ( $p s i$ ) and measures of habitat succession and quality (dist, herb, and woody; adult models 3-17, juvenile models 34-48), the additive and inter-

\section{Table 1}

A priori models correlating adult LKMR pellet counts to patch characteristics in the Lower Keys, Florida, USA, 2008. We display the number of parameters $(K),-2^{*}$ natural $\log$ of the maximum likelihood estimate $(-2 \ln L)$, Bayesian Information Criterion (BIC), change in BIC from the smallest BIC value $(\Delta \mathrm{BIC})$, and model weights $\left(w_{i}\right)$.

\begin{tabular}{|c|c|c|c|c|c|c|}
\hline Model $^{\mathrm{a}}$ & & $K$ & $-2 \ln L$ & BIC & $\triangle \mathrm{BIC}$ & $w_{i}$ \\
\hline 9 & Psi + herb + dist & 4 & 1439.1 & 1459.1 & 0.0 & 0.3 \\
\hline 27 & Proc + psi + dist & 4 & 1440.5 & 1459.8 & 0.7 & 0.2 \\
\hline 8 & Woody + herb + dist & 4 & 1447.5 & 1462.1 & 3.0 & 0.1 \\
\hline 7 & Psi + woody + herb + dist & 5 & 1438.3 & 1462.6 & 3.5 & 0.1 \\
\hline 11 & Psi + dist & 3 & 1448.6 & 1462.8 & 3.7 & 0.1 \\
\hline 17 & Herb + dist & 3 & 1448.0 & 1463.1 & 4.0 & 0.0 \\
\hline 3 & Psi & 2 & 1453.9 & 1463.2 & 4.1 & 0.0 \\
\hline 21 & Proc + dist & 3 & 1453.7 & 1463.9 & 4.8 & 0.0 \\
\hline 31 & Proc + psi & 3 & 1450.3 & 1464.6 & 5.5 & 0.0 \\
\hline 1 & Psi + woody + herb + dist + proc & 6 & 1436.0 & 1465.3 & 6.2 & 0.0 \\
\hline 16 & Herb + dist + herb $*$ dist & 4 & 1445.9 & 1465.9 & 6.8 & 0.0 \\
\hline 19 & Proc + woody + herb + dist & 5 & 1441.6 & 1466.6 & 7.5 & 0.0 \\
\hline 28 & Proc + psi + woody & 3 & 1446.9 & 1466.9 & 7.8 & 0.0 \\
\hline 4 & Dist & 2 & 1458.5 & 1467.1 & 8.0 & 0.0 \\
\hline 29 & Proc + psi + herb & 3 & 1447.1 & 1467.1 & 8.0 & 0.0 \\
\hline 20 & Proc + dist + proc $*$ dist & 4 & 1448.4 & 1467.6 & 8.5 & 0.0 \\
\hline 13 & Psi + herb & 3 & 1452.6 & 1467.6 & 8.5 & 0.0 \\
\hline 2 & Null & 1 & 1463.6 & 1467.8 & 8.7 & 0.0 \\
\hline 10 & Psi + dist + psi $*$ dist & 4 & 1448.6 & 1467.8 & 8.7 & 0.0 \\
\hline 30 & Proc + psi + proc $*$ psi & 4 & 1448.7 & 1468.1 & 9.0 & 0.0 \\
\hline 15 & Psi + woody & 2 & 1453.2 & 1468.2 & 9.1 & 0.0 \\
\hline 26 & Proc & 2 & 1460.0 & 1469.3 & 10.2 & 0.0 \\
\hline 14 & Psi + woody + psi $*$ woody & 4 & 1450.0 & 1470.0 & 10.9 & 0.0 \\
\hline 25 & Proc + herb & 3 & 1456.5 & 1471.6 & 12.5 & 0.0 \\
\hline 18 & Proc + psi + woody + herb & 5 & 1442.9 & 1471.8 & 12.7 & 0.0 \\
\hline 5 & Herb & 2 & 1462.0 & 1472.1 & 13.0 & 0.0 \\
\hline 12 & Psi + herb psi $*$ herb & 4 & 1452.6 & 1472.6 & 13.5 & 0.0 \\
\hline 6 & Woody & 3 & 1462.6 & 1472.7 & 13.6 & 0.0 \\
\hline 23 & Proc + woody & 3 & 1458.6 & 1473.7 & 14.6 & 0.0 \\
\hline 24 & Proc + herb + proc $*$ herb & 4 & 1458.0 & 1474.0 & 14.9 & 0.0 \\
\hline 22 & Proc + woody + proc $*$ woody & 4 & 1455.6 & 1475.7 & 16.6 & 0.0 \\
\hline
\end{tabular}

${ }^{\text {a }}$ Variable notation for patch attributes: null = intercept only, psi = patch shape index, woody = woody ground cover $<0.5 \mathrm{~m}$ in height $(\%)$, herb = herbaceous ground cover $<0.5 \mathrm{~m}$ in height (\%), dist = total occurrence of herbaceous species (Eleocharis cellulosa, Spartina sp., Borrichia sp., Andropogon glomeratus), proc = total no. raccoon (Procyon lotor) signs (scat or track) observed.
Table 2

A priori models correlating juvenile LKMR pellet counts to patch characteristics in the Lower Keys, Florida, USA, 2008. We display the number of parameters $(K),-2^{*}$ natural $\log$ of the maximum likelihood estimate $(-2 \ln L)$, Bayesian Information Criterion $(\mathrm{BIC})$, change in BIC from the smallest BIC value $(\Delta \mathrm{BIC})$, and model weights $\left(w_{i}\right)$.

\begin{tabular}{lllllll}
\hline Model $^{\text {a }}$ & & $K$ & $-2 \ln L$ & BIC & $\Delta$ BIC & $w_{i}$ \\
\hline 40 & Psi + herb + dist & 4 & 684.9 & 705.0 & 0.0 & 0.5 \\
45 & Psi + woody + psi $*$ woody & 4 & 685.6 & 705.6 & 0.6 & 0.4 \\
38 & Psi + woody + herb + dist & 5 & 684.9 & 710.0 & 5.0 & 0.0 \\
34 & Psi & 2 & 704.3 & 714.3 & 9.4 & 0.0 \\
32 & Psi + woody + herb + dist + proc & 6 & 684.9 & 715.0 & 10.0 & 0.0 \\
42 & Psi + dist & 3 & 700.9 & 716.0 & 11.0 & 0.0 \\
62 & Proc + psi & 3 & 703.9 & 718.9 & 14.0 & 0.0 \\
46 & Psi + woody & 3 & 704.3 & 719.3 & 14.3 & 0.0 \\
44 & Psi + herb & 3 & 704.3 & 719.4 & 14.4 & 0.0 \\
41 & Psi + dist + psi $*$ dist & 4 & 699.4 & 719.5 & 14.5 & 0.0 \\
58 & Proc + psi + dist & 4 & 700.9 & 720.9 & 15.9 & 0.0 \\
43 & Psi + herb + psi $*$ herb & 4 & 701.0 & 721.0 & 16.0 & 0.0 \\
61 & Proc + psi + proc $*$ psi & 4 & 701.2 & 721.2 & 16.3 & 0.0 \\
59 & Proc + psi + woody & 4 & 703.6 & 723.7 & 18.7 & 0.0 \\
60 & Proc + psi + herb & 4 & 703.8 & 723.9 & 18.9 & 0.0 \\
49 & Proc + psi + woody + herb & 5 & 703.6 & 728.6 & 23.6 & 0.0 \\
47 & Herb + dist + herb $*$ dist & 4 & 710.6 & 730.6 & 25.7 & 0.0 \\
39 & Woody + herb + dist & 4 & 717.2 & 737.3 & 32.3 & 0.0 \\
50 & Proc + woody + herb + dist & 5 & 713.6 & 738.7 & 33.7 & 0.0 \\
48 & Herb + dist & 3 & 729.5 & 744.5 & 39.5 & 0.0 \\
37 & Woody & 2 & 740.8 & 750.8 & 45.8 & 0.0 \\
51 & Proc + dist + proc $*$ dist & 4 & 732.5 & 752.6 & 47.6 & 0.0 \\
54 & Proc + woody & 3 & 738.0 & 753.0 & 48.1 & 0.0 \\
33 & Null & 1 & 750.5 & 755.5 & 50.5 & 0.0 \\
55 & Proc + herb + proc $*$ herb & 4 & 737.6 & 757.6 & 52.7 & 0.0 \\
53 & Proc + woody + proc $*$ woody & 4 & 737.9 & 757.9 & 52.9 & 0.0 \\
35 & Dist & 2 & 748.1 & 758.1 & 53.1 & 0.0 \\
57 & Proc & 2 & 748.0 & 758.4 & 53.4 & 0.0 \\
52 & Proc + dist & 3 & 743.6 & 758.7 & 53.7 & 0.0 \\
36 & Herb & 2 & 750.2 & 760.3 & 55.3 & 0.0 \\
56 & Proc + herb & 3 & 748.3 & 763.4 & 58.4 & 0.0 \\
\hline & & & & & & \\
& & & & & &
\end{tabular}

a Variable notation for patch attributes: null = intercept only, psi = patch shape index, woody = woody ground cover $<0.5 \mathrm{~m}$ in height $(\%)$, herb $=$ herbaceous ground cover $<0.5 \mathrm{~m}$ in height (\%), dist = total occurrence of herbaceous species (Eleocharis cellulosa, Spartina sp., Borrichia sp., Andropogon glomeratus), proc = total no. raccoon (Procyon lotor) signs (scat or track) observed.

active effects of raccoon activity (proc) and measures of habitat succession and quality (dist, herb, and woody; adult models 1826 , juvenile models 49-57), and the additive and interactive effects of patch complexity, measures of habitat succession and quality, and raccoon activity (adult models 27-31, juvenile models 58-62).

We employed an information theoretic approach for model selection using Bayesian Information Criterion (BIC) (Posada and Buckley, 2004; Ward, 2008). BIC might select simpler models compared to AIC and is more appropriate to determine which model in a set provides the best explanation of the process that generated the data (Link and Barker, 2006; Ward, 2008). We, therefore, opted to use BIC because of the simplicity of our observations and the model sets being evaluated. We used the relative difference to the smallest BIC in each model set $(\triangle \mathrm{BIC})$ and model weights $\left(w_{i}\right)$ to select the best approximating models (Burnham and Anderson, 2002; Ward, 2008). We considered models $\leqslant 2$ BIC units to compete with the best models and discarded models $>2$ BIC units as unlikely representations of the data (Kass and Raftery, 1995). We incorporated model selection uncertainty for models within 2 BIC units of the best model by presenting model average estimates and standard errors for parameters that occur in $>1$ supported model (Burnham and Anderson, 2002). We simply present model estimates and unconditional sampling variances for parameters that only occur in 1 model (Burnham and Anderson, 2002).

We derived a prediction equation by exponentiating the model averaged estimates (or model estimates when appropriate) for adult and juvenile models (Agresti, 2007). We used these equations 
to predict the influence of each models' variables on the estimated number of adult and juvenile pellets for the data set observed (Guthery and Bingham, 2007). To plot the effect of each covariate on total LKMR pellets, we held all other covariates in the prediction equation constant at their average and allowed the plotted covariate to vary throughout its range. To avoid over extrapolation of the data, we constrained plots to within the maximum range of the actual pellet counts for each age class (Guthery and Bingham, 2007).

\section{Results}

We conducted surveys of 150 patches throughout the range of LKMR from 4 January through 20 March 2008. We detected adult and juvenile LKMR pellets in 73 and 21 patches, respectively. We sampled $69221-\mathrm{m}$ radius sample units for all patches combined. The average number of sample units per patch was $46(S E=6)$. Patch area ranged from 0.09 to 51.2 ha with an average of 4.2 $(S E=0.6)$ ha. Total pellet counts per patch for adult and juvenile rabbits ranged from 0.0 to 4837.0 and 0.0 to 153.0 with an average of $97.1(S E=36.1)$ and $6.0(S E=1.8)$ per patch, respectively. Adult and juvenile pellets per ha combined ranged from 0.0 to 825.0 with an average of 25.6 ( $S E=6.6)$. For all patches, we estimated a mean patch shape index of 2.16 ( $S E=0.09$ ). Accounting for the correlation between patch area and sample effort, the mean woody cover (\%) per sample unit was $7.48(S E=1.07)$ and the mean herbaceous cover $(\%)$ per sample unit was $14.2(S E=1.91)$. We did not observe any of the four targeted genera of bunchgrasses and forbs in 21 of the 150 patches surveyed. The mean occurrence of the four bunchgrass and forb genera per sample unit was $0.42(S E=0.03)$. We observed raccoon activity in 25 of 150 patches surveyed. For patches with raccoons present the proportion of sample units with scat or tracks ranged from $1 \%$ to $13 \%$, with a mean of $3.4 \%(S E=0.01)$.

Evaluating adult rabbit pellet counts, we found models 9 and 27 best approximated the data (Table 1 ). These models had a combined $w_{i} \geqslant 0.58$ indicating there is a $58 \%$ probability one of these models provides the best explanation of the data (Burnham and Anderson, 2002; Ward, 2008). Our examination of the individual model averaged estimates (or model estimates when appropriate) and $95 \% \mathrm{CI}$ indicated only herb contained zero suggesting that the percent foliar cover of herbaceous vegetation was the only parameter that was not a relevant predictor of the total count of adult pellets (Table 3 ). We found a negative correlation between total counts of adult pellets and patch shape index (Table 3 and Fig. 2a) and between total counts of adult pellets and raccoons (Table 3 and Fig. 2c). We also found a positive correlation between total counts of adult pellets and the total occurrence of bunchgrasses and forbs (Table 3 and Fig. 2b).

Evaluating juvenile rabbit pellet counts, models 40 and 45 best approximated the data (Table 2). These two models had a combined $w_{i} \geqslant 0.90$ indicating there is a $90 \%$ probability one of these two models provides the best explanation of the data. Our examination of the individual model averaged estimates (or model esti-

Table 3

Model averaged parameter estimates and 95\% confidence intervals correlating adult Lower Keys marsh rabbit pellet counts to patch characteristics in the Lower Keys, Florida, USA, 2008.

\begin{tabular}{lrl}
\hline Parameter $^{\mathrm{a}}$ & \multicolumn{1}{l}{$\beta$} & $95 \% \mathrm{CI}$ \\
\hline Psi & -0.21 & -0.34 to -0.08 \\
Dist & 0.02 & 0.001 to 0.04 \\
Proc $^{\mathrm{b}}$ & -0.28 & -0.35 to -0.04 \\
Herb $^{\mathrm{b}}$ & 0.00 & -0.00 to 0.00 \\
\hline
\end{tabular}

${ }^{\text {a }}$ Variable notation described in Table 1.

b We present model estimates and unconditional sampling variances for parameters that occur in only one supported model.
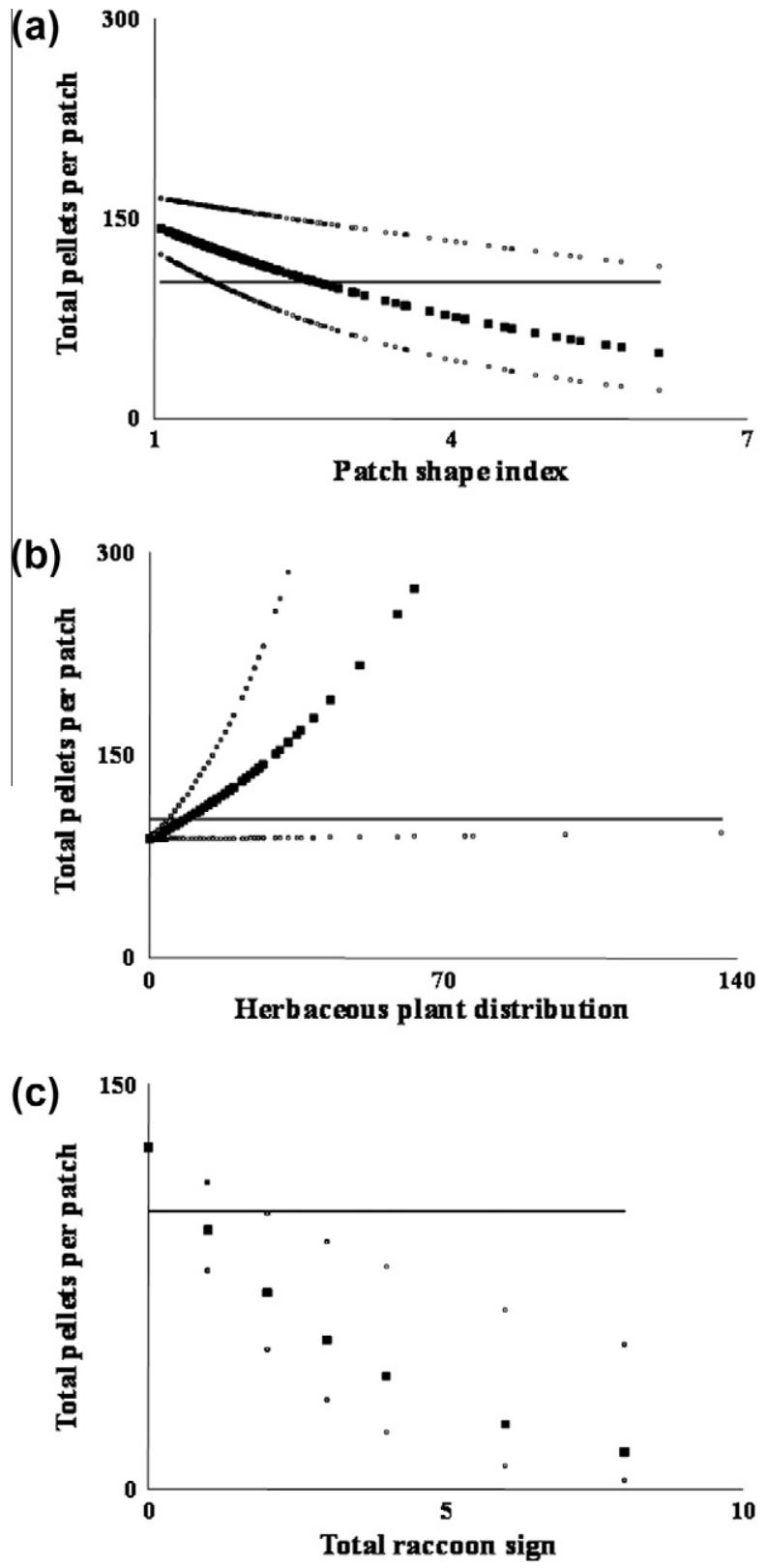

Fig. 2. Number of adult Lower Keys marsh rabbit pellets per patch and $95 \% \mathrm{CI}$ predicted as a function of the range of values recorded for (a) patch shape index, (b) the total occurrence of herbaceous plants (cord grass, sea daisy, bluestem, and spike rush), and (c) total sample units where raccoon sign (scat or track) was observed for the Lower Keys, Florida, USA, 2008. The solid black line is the number of adult rabbit pellets predicted for an average patch (size, raccoon activity, patch shape index and total occurrence of herbaceous plants).

Table 4

Model averaged parameter estimates and 95\% confidence intervals correlating juvenile Lower Keys marsh rabbit pellet counts to patch characteristics in the Lower Keys, Florida, USA, 2008.

\begin{tabular}{lcl}
\hline Parameter $^{\mathrm{a}}$ & $\beta$ & $95 \% \mathrm{CI}$ \\
\hline Psi & -0.78 & -1.08 to -0.47 \\
Dist $^{\mathrm{b}}$ & 0.06 & 0.03 to 0.09 \\
Herb $^{\mathrm{b}}$ & 0.00 & -0.00 to 0.00 \\
Woody $^{\mathrm{b}}$ & -0.001 & -0.00 to 0.00 \\
Psi $*$ Woody $^{\mathrm{b}}$ & 0.00 & -0.00 to 0.00 \\
\hline
\end{tabular}

\footnotetext{
a Variable notation described in Table 2.

b We present model estimates and unconditional sampling variances for parameters that occur in only one supported model.
} 

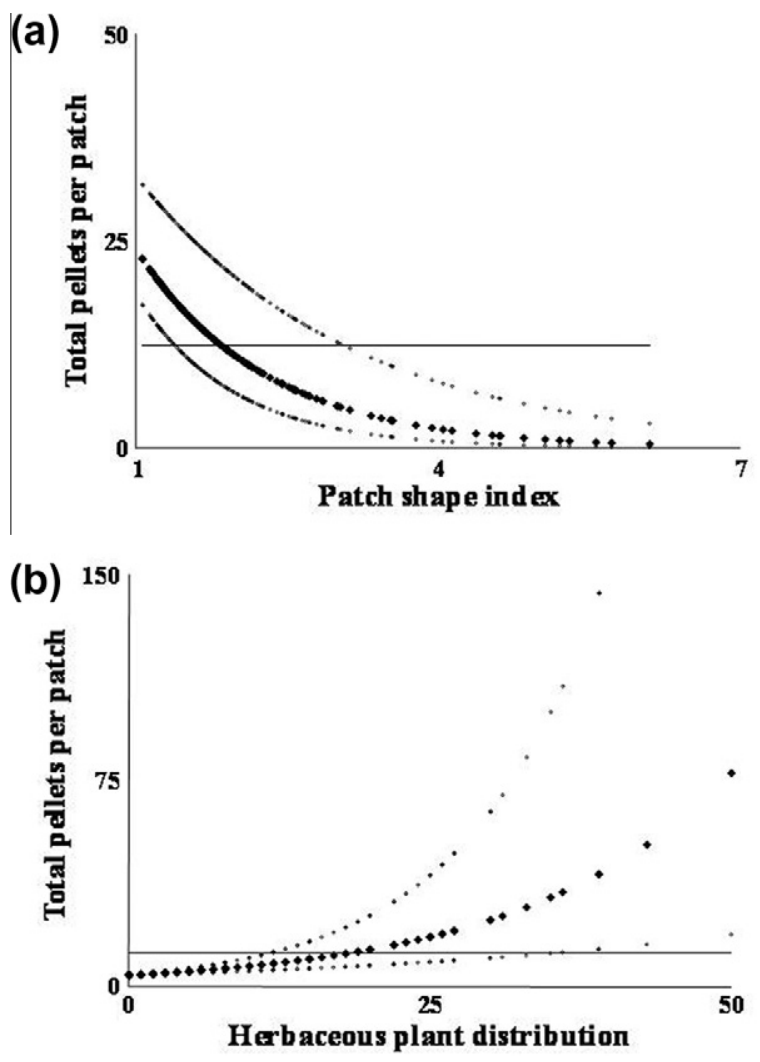

Fig. 3. Number of juvenile Lower Keys marsh rabbit pellets per patch and $95 \% \mathrm{CI}$ predicted as a function of the range of values recorded for (a) patch shape index and (b) total occurrence of herbaceous plants (cord grass, sea daisy, bluestem, and spike rush) for the Lower Keys, Florida, USA, 2008. The solid black line is the number of juvenile rabbit pellets predicted for an average patch (size, patch shape index and total occurrence of herbaceous plants).

mates when appropriate) and 95\% CI indicated herb, woody, and psi*woody contained zero suggesting the percent foliar cover of herbaceous and woody vegetation and the interaction between patch shape index and the percent foliar cover of woody vegetation were not relevant predictors of the total count of juvenile pellets (Table 4). We found a negative relationship between the total count of juvenile pellets and patch shape index (Fig. 3a) and a positive relationship between the total count of juvenile pellets and the total occurrence of bunchgrasses and forbs (Fig. 3b).

\section{Discussion}

Based on our regression analysis, we found a negative relationship between increasing patch edge, indicated by an increase in patch shape index, and both adult and juvenile LKMR. Edge effects due to habitat fragmentation and succession have not previously been investigated for the LKMR. The effects of edge on other species, particularly songbirds, are numerous and might include reduced density, distribution, and dispersal ability and increased rates of predation and parasitism (Yahner, 1988). Lower densities of adult and juvenile LKMR in patches with high amounts of edge suggest these patches would have a higher probability of extinction.

We found positive relationships between both adult and juvenile LKMR and the distribution of four genera of herbaceous plants that previously were found to be important to LKMRs for food, cover, and nesting (Faulhaber et al., 2008; Forys and Humphrey, 1999b). Numerous measures of herbaceous vegetation including availability of bunchgrasses and forbs and ground vegetation height and thickness have all been associated with consistency of LKMR patch occupancy, habitat use and diurnal form use (Faulhaber et al., 2008; Forys and Humphrey, 1999b; Perry, 2006). It was suggested by Forys and Humphrey (1999b) that thick foliar cover was important to the LKMR for nesting and also provided protection from predators, including raccoons. Our results are consistent with these studies and suggest patches in a later successional state, characterized by a reduction in the number of bunchgrasses and forbs important to the LKMR, might result in decreased rabbit densities, thus potentially reducing patch persistence and increasing extinction risk.

We found a negative relationship between raccoons and adult LKMR, but we did not find a relationship between raccoons and juvenile LKMR. Raccoons might affect LKMR directly through mortality or indirectly when rabbits avoid areas with high levels of predators (Banks et al., 1999). Direct mortality of LKMR due to raccoon predation has not been supported by data on adult mortality (Forys and Humphrey, 1999a); however, total counts of adult LKMRs might be lower in areas with high raccoon activity because adult rabbits avoid areas with high densities of potential nest predators. Indirect effects of predation have been shown for European rabbits (Oryctolagus cuniculus) in Australia where rabbits were observed farther from refuge and maintained higher body condition in predator removal areas (Banks et al., 1999). An alternative explanation is that raccoons and adult LKMR use different habitats. To test this hypothesis we conducted a post hoc analysis comparing the number of patches with raccoons and rabbits $(N=19)$ to patches with raccoons and no rabbits $(N=6)$ using a chi-square test of independence. We found rabbits and raccoons use the same patches more than expected $\left(\chi^{2}=6.8, P=0.01\right)$. We then compared patches without raccoons or rabbits $(N=71)$ to patches with raccoons and no rabbits $(N=6)$ and found raccoons use patches without rabbits less than expected $\left(\chi^{2}=54.9, P<0.001\right)$. These results suggest that the statistical relationship between raccoons and rabbits was not a product of different patch use by these two species.

We further hypothesized that increased raccoon activity was associated with increasing edge or patch complexity and hardwood encroachment (Dorney, 1954; McCleery et al., 2005; Riley et al., 1998; Smith and Engeman, 2002). To test this hypothesis, we conducted additional post hoc analyses using Spearman's rank correlation coefficients. We found a significant ( $\rho=0.16, P=0.03$ ), positive correlation between patch shape index and raccoon activity and a significant $(\rho=0.25, P=0.001)$, positive correlation between patch shape index and the total percent foliar cover of woody vegetation, thus supporting our hypothesis that raccoon activity is positively associated with edge effects due to habitat fragmentation and succession.

The lack of support for a relationship between juvenile LKMRs and raccoons could be due to the paucity of data as only 21 of 150 patches contained juvenile rabbits, of those only five contained raccoons. Therefore, even the simplest models would produce a parameter to data ratio far below what is statistically feasible and would cause a high probability of Type I or II error (Burnham and Anderson, 2002). Indirect effects of raccoons might be less prevalent as juvenile rabbits are not reproductive and would not need to selectively avoid areas with high levels of potential nest predators. Further, our measure of raccoon activity is based on an index that does not account for lack of detection at individual sample units thus potentially introducing negative bias in our estimates of raccoon activity (Anderson, 2001). While the use of an index as a predictor variable does not invalidate model results (Anderson, 2001), this limitation to our data could reduce, in the case of adult rabbits, or mask, in the case of juvenile rabbits, the relationship between raccoon activity and LKMRs. While our data do not elucidate 
the mechanism by which raccoons affect LKMRs, our results support anecdotal observations that raccoons pose a threat to the LKMR (Dorney, 1954; USFWS, 2007).

\section{Conclusions}

Our results suggest that amount of edge, habitat succession and quality, and raccoon activity pose a threat to the persistence and recovery of the LKMR. Recovery efforts should focus on reducing patch edge by simplifying patch boundaries, improving habitat quality, and reducing the prevalence of raccoons in LKMR patches. Our results provide support for habitat management strategies, such as removal of overstory hardwood vegetation and prescribed fire that would reduce patch edge, slow or reverse the rate habitat succession and improve the amount and diversity of herbaceous bunchgrasses and forbs (USFWS, 2007). Our post hoc analyses indicate these efforts might also serve to reduce raccoon activity. Because our results are correlative and do not provide direct evidence of causation, the recovery efforts we have recommended should be implemented in carefully controlled experiments with proper monitoring. Findings from these experiments could provide direct evidence of the influence of edge, habitat succession and quality, and raccoon activity on local LKMR densities while informing an adaptive resource management program for this endangered subspecies (Lancia et al., 1996).

The ability of patch shape indices, measures of particular herbaceous plant species and raccoon activity to predict LKMR pellet counts indicates these parameters are important indicators of patch quality and should be included in long-term monitoring strategies. Likewise, these variables could provide useful information in selecting and prioritizing which LKMR patches receive recovery actions and for monitoring the effectiveness of those activities. Further, the current monitoring protocol does not track indicators of habitat quality (USFWS, 2007) and the time to detect a population decline is not known for this subspecies. This scenario, given on-going habitat degradation through succession, could result in a failure to detect critical habitat degradation (Doak, 1995).

We demonstrate that habitat succession, a natural process often disrupted or accelerated by human intervention and a native generalist predator can have great influence on the recovery of an endangered species. Our study also demonstrates reliance upon protectionist dogma alone will be insufficient to recover endangered species and that failure to intervene to reverse natural processes such as habitat succession might result in species extinction (Doak, 1995). Finally, we provide empirical evidence to support the use of a metapopulation framework that incorporates successional processes on patch dynamics in the study of species threatened by habitat loss and fragmentation that also occur in successional habitats (Amarasekare and Possingham, 2001; Stelter et al., 1997), including endangered lagomorphs.

\section{Acknowledgments}

We received financial support from the US Department of Defense and the US Fish and Wildlife Service. P. Schmidt received support from Texas A\&M University, the Alfred P. Sloan Minority PhD. Program, and the Student Career Experience Program of the US Fish and Wildlife Service. We would like to thank C. Backlund, E. Barham, and G. Kenny at the Naval Air Station Key West Environmental Office for providing access and logistical support and the US Fish and Wildlife Service for access to the Lower Florida Keys Refuges. We are grateful to A. Dedrickson, R. Loughridge, H. Murray, and D. Schmidt for field support, M. Boggess, B. Collier, L. Walters, and A. Wiley for analytical assistance, and A. Smith, B. Forys and 1 anonymous reviewer for comments on this manuscript.

\section{References}

Agresti, A., 2007. An Introduction to Categorical Data Analysis, second ed. John Wiley and Sons, Inc., Hoboken, New Jersey.

Alexander, T.R., Dickson III, J.H., 1970. Vegetational changes in the National Key Deer Refuge. Quart. J. Florida Acad. Sci. 33, 81-89.

Amarasekare, P., Possingham, H., 2001. Patch dynamics and metapopulation theory: a case of successional species. J. Theor. Biol. 209, 333-344.

Anderson, D.R., 2001. The need to get the basics right in wildlife field studies. Wildlife Soc. B. 49, 1294-1297.

Banks, P.B., Hume, I.D., Crowe, O., 1999. Behavioural, morphological and dietary response of rabbits to predation risk from foxes. Oikos 85, 247-256.

Burnham, K.P., Anderson, D.R., 2002. Model Selection and Multi-Model Inference: A Practical Information-Theoretic Approach, second ed. Springer Science, LLC, New York, New York.

Chen, E., Gerber, J.F., 1990. Climate. In: Myers, R.L., Ewel, J.J. (Eds.), Ecosystems of Florida. University of Central Florida Press, Orlando, pp. 11-34.

Dickson III, J.H., 1955. An Ecological Study of the Key Deer. Technical Bulletin \#3, Federal Aid Project W-34-R. Florida Game and Freshwater Fish Commission, Tallahassee.

Dijak, W.D., Thompson III, F.R., 2000. Landscape and edge effects on the distribution of mammalian predators in Missouri. J. Wildlife Manage. 64, 209-216.

Doak, D.F., 1995. Source-sink models and the problem of habitat degradation: general models and applications to the Yellowstone grizzly. Conserv. Biol. 9, $1370-1379$.

Dorney, R.S., 1954. Ecology of marsh raccoons. J. Wildlife Manage. 18, 217-225.

Ellner, S.P., Fussmann, G., 2003. Effects of successional dynamics on metapopulation persistence. Ecology 84, 882-889.

ESRI, 2008. ArcGIS 9.X. Environmental Systems Research Institute, Inc., Redlands, California.

Faulhaber, C.A., 2003. Updated Distribution and Reintroduction of the Lower Keys Marsh Rabbit. Thesis, Texas A\&M University, College Station.

Faulhaber, C.A., Perry, N.D., Silvy, N.J., Lopez, R.R., Frank, P.A., Hughes, P.T., Peterson, M.J., 2007. Updated distribution of the Lower Keys marsh rabbit. J. Wildlife Manage. 71, 208-212.

Faulhaber, C.A., Silvy, N.J., Lopez, R.R., LaFever, D.H., Frank, P.A., Peterson, M.J., 2008. Diurnal habitat use of Lower Keys marsh rabbits. J. Wildlife Manage. 72, 11611167.

Forys, E.A., 1995. Metapopulations of Marsh Rabbits: A Population Viability Analysis of the Lower Keys Marsh Rabbit (Sylvilagus palustris hefneri), Dissertation, University of Florida, Gainesville.

Forys, E.A., Humphrey, S.R., 1996. Home range and movements of the Lower Keys marsh rabbit in a highly fragmented habitat. J. Mammal. 77, 1042-1048.

Forys, E.A., Humphrey, S.R., 1999a. Use of population viability analysis to evaluate management options for the endangered Lower Keys marsh rabbit. J. Wildlife Manage. 63, 251-260.

Forys, E.A., Humphrey, S.R., 1999b. The importance of patch attributes and context to the management and recovery of an endangered lagomorph. Landscape Ecol. 14, 177-185.

Guthery, F.S., Bingham, R.L., 2007. A primer on interpreting regression models. J. Wildlife Manage. 71, 684-692.

Hackländer, K., Ferrand, N., Alves, P.C., 2008. Overview of lagomorph research: what we have learned and what we still need to do. In: Alves, P.C., Ferrand, N., Hackländer, K. (Eds.), Lagomorph Biology: Evolution, Ecology, and Conservation. Springer-Verlag, Berlin, Germany, pp. 381-391.

Hardt, R.A., Forman, R.T.T., 1989. Boundary effects on woody colonization of reclaimed surface mines. Ecology 70, 1252-1260.

Harrison, S., 1994. Metapopulations and conservation. In: Edwards, P.J., May, R., Webb, N.R. (Eds.), Large-Scale Ecology and Conservation Biology. Blackwell Sci. Publ., Boston, Massachusetts, pp. 111-128.

Hastings, A., 2003. Metapopulation persistence and age-dependent disturbance or succession. Science 301, 1525-1526.

IUCN, 2010. IUCN Red List of Threatened Species. Version 2010.1. <http:// www.iucnredlist.org> (accessed 24.03.10)

Jennings, J.B., Kennedy, M.L., Houston, A.E., Carver, B.D., 2006. Predation on artificial nests of northern bobwhites, Colinus virginianus, by mammalian mesopredators: does the problem-individual paradigm fit? Can. Field Nat. 120, 452-456.

Johnson, M.P., 2000. The influence of patch demographics on metapopulations, with particular reference to successional landscapes. Oikos 88, 67-74

Kasper, K.C., 2005. Hurricane Wilma in the Florida Keys. National Weather Service. <http://www.srh.noaa.gov/key/HTML/wilma/wilma.html> (accessed 15.05.09).

Kass, R.A., Raftery, A.E., 1995. Bayes factors. J. Am. Stat. Assoc. 90, 773-795.

Lancia, R.A., Braun, C.E., Collopy, M.W., Dueser, R.D., Kie, J.G., Martinka, C.J., Nichols, J.D., Nudds, T.D., Porath, W.R., Tilghman, N.G., 1996. ARM! For the future: adaptive resource management in the wildlife profession. Wildlife Soc. B. 24, 436-442.

Lazell Jr., J.D., 1984. A new marsh rabbit (Sylvilagus palustris) from Florida's Lower Keys. J. Mammal. 65, 26-33.

Levins, R., 1970. Extinction. In: Gerstenhaber, M. (Ed.), Some Mathematical Questions in Biology, Lecture Notes on Mathematics in the Life Sciences. The American Mathematical Society, Providence, Rhode Island, pp. 75-107.

Link, W.A., Barker, R.J., 2006. Model weights and the foundations of multimodel inference. Ecology 87, 2626-2635.

Litvaitis, J.A., 1993. Response of early successional vertebrates to historic changes in land use. Conserv. Biol. 7, 866-873. 
Litvaitis, J.A., Villafuerte, R., 1996. Factors affecting the persistence of New England cottontail metapopulation: the role of habitat management. Wildlife Soc. B. 24, 686-693.

Lopez, R.R., Silvy, N.J., Labisky, R.F., Frank, P.A., 2003. Hurricane impacts on Key deer in the Florida Keys. J. Wildlife Manage. 67, 280-288.

McCleery, R.A., Foster, G.W., Lopez, R.R., Peterson, M.J., Forrester, D.J., Silvy, N.J., 2005. Survey of raccoons on Key Largo, Florida, USA, for Baylisascaris procyonis. J. Wildlife Dis. 41, 250-252.

McGarigal, K., Marks, B.J., 1995. FRAGSTATS: Spatial Pattern Analysis Program for Quantifying Landscape Structure. USDA Forest Service, Pacific Northwest Research Station. General Technical Report GTR-PNW-351, Portland, Oregon.

McGarry MacAulay, G., Leary, T.J., Sargent, F.J., Colby, M.M., Prouty, E.J., Friel, C.A., 1994. Advanced Identification of Wetlands in the Florida Keys, Final Report. Florida Department of Environmental Protection, Division of Marine Resources, Florida Marine Research Institute, Marathon.

Nielsen, C.L.R., Wakamiya, S.M., Nielsen, C.K., 2008. Viability and patch occupancy of a swamp rabbit metapopulation at the northern edge of its distribution. Biol. Conserv. 141, 1043-1054.

Perry, N.D., 2006. Lower Keys Marsh Rabbit and Silver Rice Rat: Steps Towards Recovery. Thesis, Texas A\&M University, College Station.

Posada, D., Buckley, T.R., 2004. Model selection and model averaging in phylogenetics: advantages of Akaike Information Criterion and Bayesian approaches over likelihood ratio test. Syst. Biol. 53, 793-808.

Riley, S.P.D., Hadidian, J., Manski, D.A., 1998. Population density, survival and rabies in raccoons in an urban national park. Can. J. Zool. 76, 1153-1164.

Schmidt, J.A., McCleery, R.A., Silvy, N.J., Lopez, R.R., Schmidt, P.M., in press. Population estimation and monitoring of an endangered lagomorph. J. Wildlife Manage.

Smith, A.T., 2008. Conservation of endangered lagomorphs. In: Alves, P.C., Ferrand, N., Hackländer, K. (Eds.), Lagomorph Biology: Evolution, Ecology, and Conservation. Springer-Verlag, Berlin, Germany, pp. 297-315.
Smith, H.T., Engeman, R.M., 2002. An extraordinary raccoon density (Procyon lotor) at an urban park. Can. Field Nat. 116, 636-639.

Stelter, C.M., Reich, M., Grimm, V., Wissel, C., 1997. Modelling persistence in dynamic landscapes: lessons from a metapopulation of the grasshopper Bryodema tuberculata. J. Anim. Ecol. 66, 508-518.

Thomas, C.D., 1994. Extinction, colonization, and metapopulations: environmental tracking by rare species. Conserv. Biol. 8, 373-378.

Urban, D., 1970. Raccoons, populations, movement patterns, and predation on a managed waterfowl marsh. J. Wildlife Manage. 34, 372-382.

United States Fish and Wildlife Service, 1990. Endangered and threatened wildlife and plants; endangered status for the Lower Keys marsh rabbit and threatened status for the squirrel chimney cave shrimp. Fed. Register 55, 25588-25591.

United States Fish and Wildlife Service, 1999. South Florida Multi-Species Recovery Plan. United States Fish and Wildlife Service, Atlanta, Georgia.

United States Fish and Wildlife Service, 2000. Fire Management Plan: National Key Deer Refuge, Big Pine Key, Florida.

United States Fish and Wildlife Service, 2007. Lower Keys Marsh Rabbit 5-year Review. <http://ecos.fws.gov/> (accessed 12.05.09).

Viele, J., 1996. The Florida Keys: A History of the Pioneers. Pineapple Press, Sarasota, Florida.

Ward, E., 2008. A review and comparison of four commonly used Bayesian and maximum likelihood model selection tools. Ecol. Model. 211, 1-10.

Williams, D.F., Kelly, P.A., Hamilton, L.P., Lloyd, M.R., Williams, E.A., Youngblom, J.J. 2008. Recovering the endangered riparian brush rabbit (Sylvilagus bachmani riparius): reproduction and growth in confinement and survival after translocation. In: Alves, P.C., Ferrand, N., Hackländer, K. (Eds.), Lagomorph Biology: Evolution, Ecology and Conservation. Springer-Verlag, Berlin, Germany, pp. 349-361.

Yahner, R.H., 1988. Changes in wildlife communities near edges. Conserv. Biol. 2, 333-339. 